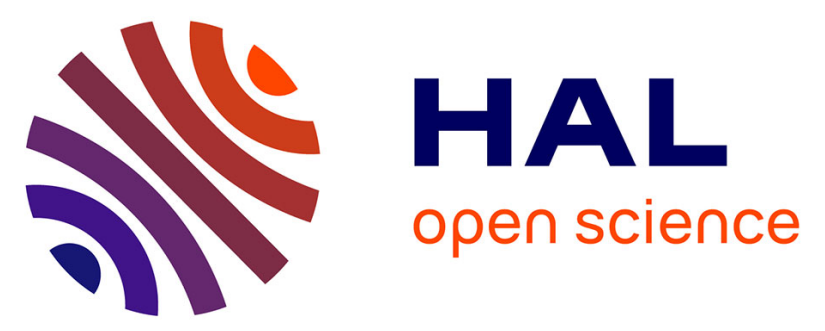

\title{
Improvement of electrostrictive properties of a polyether-based polyurethane elastomer filled with conductive carbon black
}

K. Wongtimnoi, B. Guiffard, A. Bogner-van de Moortèle, L. Seveyrat, C. Gauthier, J.-Y. Cavaillé

\section{To cite this version:}

K. Wongtimnoi, B. Guiffard, A. Bogner-van de Moortèle, L. Seveyrat, C. Gauthier, et al.. Improvement of electrostrictive properties of a polyether-based polyurethane elastomer filled with conductive carbon black. Composites Science and Technology, 2011, 71 (6), pp.885. 10.1016/j.compscitech.2011.02.003 . hal-00736292

\section{HAL Id: hal-00736292 \\ https://hal.science/hal-00736292}

Submitted on 28 Sep 2012

HAL is a multi-disciplinary open access archive for the deposit and dissemination of scientific research documents, whether they are published or not. The documents may come from teaching and research institutions in France or abroad, or from public or private research centers.
L'archive ouverte pluridisciplinaire HAL, est destinée au dépôt et à la diffusion de documents scientifiques de niveau recherche, publiés ou non, émanant des établissements d'enseignement et de recherche français ou étrangers, des laboratoires publics ou privés. 


\section{Accepted Manuscript}

Improvement of electrostrictive properties of a polyether-based polyurethane elastomer filled with conductive carbon black

K. Wongtimnoi, B. Guiffard, A. Bogner-Van de Moortèle, L. Seveyrat, C. Gauthier, J.-Y. Cavaillé

PII: S0266-3538(11)00070-4

DOI: 10.1016/j.compscitech.2011.02.003

Reference: CSTE 4928

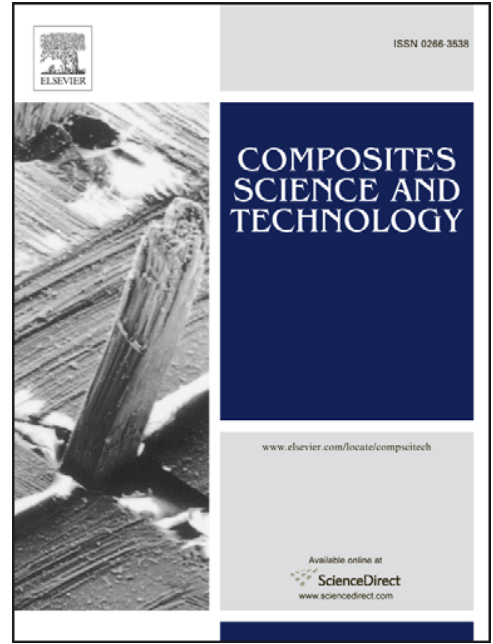

To appear in:

Composites Science and Technology

Received Date:

24 November 2010

Revised Date:

4 February 2011

Accepted Date:

13 February 2011

Please cite this article as: Wongtimnoi, K., Guiffard, B., Bogner-Van de Moortèle, A., Seveyrat, L., Gauthier, C., Cavaillé, J.-Y., Improvement of electrostrictive properties of a polyether-based polyurethane elastomer filled with conductive carbon black, Composites Science and Technology (2011), doi: 10.1016/j.compscitech.2011.02.003

This is a PDF file of an unedited manuscript that has been accepted for publication. As a service to our customers we are providing this early version of the manuscript. The manuscript will undergo copyediting, typesetting, and review of the resulting proof before it is published in its final form. Please note that during the production process errors may be discovered which could affect the content, and all legal disclaimers that apply to the journal pertain. 


\section{Title}

Improvement of electrostrictive properties of a polyether-based polyurethane elastomer filled with conductive carbon black

\section{Authors and Affiliations}

K. Wongtimnoi ${ }^{\mathbf{a}^{*}}$, B. Guiffard $\mathbf{b}^{*}$, A. Bogner-Van de Moortèle ${ }^{\mathbf{a}}$, L. Seveyrat ${ }^{\mathbf{b}}$, C. Gauthier $^{\mathbf{a}}$ and J.-Y. Cavaille $\mathrm{e}^{\mathrm{a} *}$

${ }^{a}$ MATErials Engineering and Science (MATEIS), INSA Lyon, CNRS-UMR 5510,

Bâtiment Blaise Pascal, 7 av. Jean-Capelle, F-69621 Villeurbanne cedex, France

b Laboratoire de Génie Electrique et Ferroélectricité (LGEF), INSA Lyon, Bâtiment

Gustave Férrié, 8 rue de la Physique, F-69621 Villeurbanne cedex, France

* Corresponding author:

Komkrisd Wongtimnoi,

E-mail: komkrisd.wongtimnoi@insa-lyon.fr, Tel: +33472436374

Benoit Guiffard,

E-mail: benoit.guiffard@insa-lyon.fr, Tel: +33472438720

Jean-Yves Cavaillé,

E-mail: jean-yves.cavaille@insa-lyon.fr, Tel: +33472438803 


\begin{abstract}
The electrostrictive properties of a polyether-based polyurethane elastomer and its corresponding composites filled with conductive carbon black (CB) were studied by measuring the thickness strain $S_{Z}$ induced by external electric fields $E$. For films with thicknesses of approximately $50 \mu \mathrm{m}$, the apparent electrostrictive coefficient $M$ was measured at low electric fields, $E \leq 4 \mathrm{~V} / \mu \mathrm{m}$, and different $\mathrm{CB}$ contents (up to a volume fraction of $2 \%$ ). Dielectric measurements in $\mathrm{AC}$ mode were performed in order to determine the percolation threshold $f_{c}$, which was $1.25 \mathrm{v} \%$. This optimal volume fraction yielded a remarkable threefold increase in $M$, associated with an increase of the dielectric constant by a factor 7 , in comparison with pure PU. This enhancement of the electric field-induced strain and apparent electrostriction was mainly triggered by an increase of the dielectric constant, even if the intrinsic electrostriction coefficient $Q$ was decreased. The nanocomposites thus seem to be very attractive for low-frequency electromechanical applications. Above $f_{c}$, their conductivity was raised and their electrostrictive activity lost. Finally, there is a good agreement between the experimentally determined dependence on the $\mathrm{CB}$ content of the $M$ coefficient and the theoretical estimation calculated from dielectric and mechanical measurements.
\end{abstract}

Keywords: A. Polyether-based polyurethane; A. Nanocomposite; B. Electrostriction; B. Electromechanical properties; B. Dielectric constant 


\section{Introduction}

For the last twenty years, electroactive polymers (EAPs) have devoted much attention since they undergo a huge deformation when subjected to an external electric field [1]. Even if more classical piezoelectric ceramics remain more efficient in terms of energy conversion by weight unit, their stiffness and brittleness limit their use when very small displacements are required. Moreover, the processing of polymeric materials is often easier as it does not require high temperatures, like ceramics. This makes EAPs attractive for integration inside microelectromechanical systems (MEMS).

EAPs are particularly interesting for electromechanical applications such as micro-actuators, robotics, submarines, acoustics elements, noise and vibration control applications, etc. [2]. Recently, electroactive polymers have been used for energyharvesting applications and mechano-electrical conversion [3]. However, the main drawback of EAPs is their weak electromechanical coupling: high electric fields up to $150 \mathrm{MV} / \mathrm{m}$ are required to reach $2-10 \%$ strain in dielectric elastomers such as acrylics [4].

Recently, rather large deformations were attained by certain polyurethanes (PUs) under electric fields of $20 \mathrm{MV} / \mathrm{m}$ [5]. This was possible due to PU having a high dielectric constant, rendering it possible for a strong polarization to be induced under an external electric field. The obtained dipole-dipole interactions gave rise to a rather large electrostriction.

Another way to increase the effective dielectric constant consists in incorporating electrically conducting particles $[6,7]$. Below the percolation threshold, the dielectric constant $\varepsilon^{\prime}{ }_{r}$ increases rapidly with the concentration of particles [8]. It is thus of importance to precisely analyze the impact of added fillers such as carbon black 
in a polyurethane matrix. Following this idea, the aim of the present study was to determine the influence of $\mathrm{CB}$ as filler affecting on the electrical, mechanical and electromechanical properties of a PU host polymer.

\section{Theoretical background}

Classical electrostriction experiments are generally performed on thin polymer samples coated with conducting metallic or organic layers on their two opposite faces. This differs from magnetostriction experiments where the magnetic field is applied without any contact with the sample [9]. As a result, global electrostriction is the sum of two distinct contributions. The first will hereafter be referred to as $S_{E}$ and corresponds to true electrostriction (which mainly results from interactions between dipoles induced inside the material by the electric field), while the second, known as $S_{\text {Max }}$, is developed from the electrostatic stress (Maxwell) between the two electrodes. In fact, the latter contribution is due to the interaction between the free charges on the electrodes (Coulomb interactions).

In polarizable materials with a homogeneous space-charge density, $S_{E}$ may be expressed as [10]

$$
S_{E}=Q \cdot P^{2}
$$

where $Q$ is the intrinsic electrostrictive coefficient, and $P$ is the polarization induced by an electric field $E$ in a dielectric material. Thus, for a linear dielectric, $P$ is written as

$$
P=\varepsilon_{0} \cdot\left(\varepsilon^{\prime}{ }_{r}-1\right) . E
$$

where $\varepsilon_{r}^{\prime}$ is the real part of the relative dielectric permittivity (also called the dielectric constant) and the electrostrictive strain may be expressed as

$$
S_{E}=Q \cdot \varepsilon_{0}^{2} \cdot\left(\varepsilon^{\prime}{ }_{r}-1\right)^{2} \cdot E^{2}
$$


On the other hand, the strain due to the Maxwell stress, the so-called electrostatic strain $S_{M a x}$, can be written as [11]

$$
S_{M a x}=\frac{-\mathcal{E}_{r}^{\prime} \cdot \varepsilon_{0} \cdot E^{2}}{Y}
$$

where $Y$ is the Young modulus. The apparent global strain is then given by

$$
S=S_{E}+S_{M a x}=M \cdot E^{2}
$$

where $M$ is the so-called apparent electrostrictive coefficient, here for the thickness strain direction along which the electric field is applied. In fact, these two main contributions are difficult to separate from each other by experiments.

For electrostrictive (polar) polymers such as polyurethane, poly(vinylidene fluoride) or PVDF, and the poly(vinylidene fluoride-trifluoroethylene) copolymer or $\mathrm{P}(\mathrm{VDF}-\mathrm{TrFE}), S_{E}$ may become largely predominant as compared to $S_{M a x}$, and $M$ is related to the electrostrictive coefficient $Q$ through

$M=\varepsilon_{0}^{2} \cdot\left(\varepsilon_{r}^{\prime}{ }_{r}-1\right)^{2} \cdot Q$

Besides, several research groups have experimentally observed that the intrinsic electrostrictive coefficient $Q$ defined in Eq.(1) is inversely proportional to the product of the Young modulus and dielectric permittivity [12-14] according to

$Q \propto \frac{1}{\varepsilon_{0} \cdot \varepsilon_{r}^{\prime} \cdot Y}$

Thus, for a dielectric material, for which $\varepsilon_{r}{ }_{r} \gg 1, M$ is proportional to the dielectric constant and inversely proportional to the Young's modulus $Y$ of the material [15]:

$M \propto \frac{\varepsilon_{0} \cdot \varepsilon_{r}^{\prime}}{Y}$ 
Eq.(8) clearly shows that a good compromise between dielectric constant and softness has to be found to obtain good electromechanical activity. For any elastomeric materials with small $\varepsilon_{r}^{\prime}$, e.g. silicone, acrylics, isoprene natural rubber latex [16], the true electrostrictive effect is always assumed to be negligible, i.e. $S_{E} \approx 0$. Hence, the strain results mainly from the Maxwell stress.

Within the scope of this paper, the electrostrictive performances of a polyurethane elastomer and its composites with carbon black as electrically conducting nanoparticles were studied for an increasing dielectric constant. The investigated samples were thin films $50 \mu \mathrm{m}$ thick. All external electric stimuli and electromechanical responses were applied and measured only along the thickness direction $(Z)$. The electrical conductivity, dielectric constant and mechanical properties are presented prior to the electrostriction measurements, and the electrostrictive coefficients $Q$ and $M$ are validated with relative theoretical equations.

\section{Experimental section}

\subsection{Material preparations}

The polymer used in this study was a polyether-based aromatic thermoplastic polyurethane (PU), Estane 58888 NAT 021, purchased from Lubrizol Corporation [17]. Carbon black (CB), under the commercial trademark Vulcan XC72R in fluffy form having a surface area of $254 \mathrm{~m}^{2} / \mathrm{g}$ and a DBPA (Dibutyl phthalate absorption) of 192 $\mathrm{cm}^{3} / 100 \mathrm{~g}$ [18], was provided by the Cabot Corporation. The CB nanoparticles have an average diameter of $30 \mathrm{~nm}$ for the primary particles and a specific gravity of 1.80 [19].

The composites were cast from solutions: the first step consisted in dissolving and homogenizing the PU granules in $\mathrm{N}, \mathrm{N}$-dimethylformamide (DMF) at $80{ }^{\circ} \mathrm{C}$ for 90 min. In the mean time, various volume fractions of CB were dispersed in DMF using 
an ultrasonic probe (UP400S from Hielscher) for $10 \mathrm{~min}$. Subsequently, the two solutions were mixed together, heated and stirred until a viscous solution was obtained. The solution was spread with a film maker (Casting knife, from Elcometer) to form a thin film $\sim 50 \mu \mathrm{m}$ thick and then dried at $60{ }^{\circ} \mathrm{C}$ for one day. Finally, the obtained films were annealed at $130{ }^{\circ} \mathrm{C}$ for 3 hours to eliminate the residual DMF. Samples were cut according to the requirements of the characterization techniques.

\subsection{Characterization techniques}

\subsubsection{CB Dispersion}

The dispersion of carbon black was checked by scanning electron microscopy (SEM) on an FEI XL30 FEG ESEM. Samples were fractured in liquid nitrogen after which the fractured cross-sections were gold-coated by plasma sputtering prior to the SEM observations.

\subsubsection{Mechanical properties}

The mechanical behavior of the composite films was measured with a multifunctional dynamic mechanical analyzer, Eplexor ${ }^{\circledR}$ from Gabo, in simple tensile mode. The films were cut into $10 \times 40 \mathrm{~mm}^{2}$ rectangular specimens, which were fixed in their two ends thus leaving $20 \mathrm{~mm}$ long for the measurements. The tests were carried out with an elongation speed of $24 \mathrm{~mm} / \mathrm{min}$ at room temperature under air.

\subsubsection{Electrical conductivity and dielectric properties}

Prior to the electrical measurements, the films were coated with gold on their two main faces. The complex conductivity was measured with a Solartron 1296 impedance-meter from Schlumberger. The average potential was set at $1 \mathrm{Vrms}$, and a frequency scan was performed in the range 0.1 to $10^{6} \mathrm{~Hz}$ at room temperature. From 
this, the dielectric constant $\varepsilon^{\prime}{ }_{r}$ and the complex electrical conductivity $\sigma^{*}$ could be determined.

\subsubsection{Electromechanical response (global electrostriction)}

The electric field-induced strain $S_{Z}$ was determined at room temperature using a laser interferometer (Agilent 10889B) with a $10 \mathrm{~nm}$ precision. A film specimen was positioned between two circular electrodes with 20-mm diameters to which an alternative electrical potential (triangular function) was applied at a frequency of 0.1 Hz. A mirror was placed on the upper electrode to reflect the laser beam in order to determine the displacement in real time. The electrical potential was generated by a functional generator (Agilent 33220A) and amplified 1000 times by a lock-in hightension amplifier (Trek 10/10B).

\section{Results and discussion}

4.1 CB dispersion in the polymer matrix

---Fig.1---

In order to verify the dispersion state of carbon black in the polyurethane matrix, a composite film of $0.65 \mathrm{v} \% \mathrm{CB} / \mathrm{PU}$ was observed by SEM. According to Fig.1(A), the sample exhibits a rather good CB dispersion within the matrix. However, a higher magnification, as shown in Fig.1(B), revealed aggregates smaller than $500 \mathrm{~nm}$, as well as individualized CB particles of about $30 \mathrm{~nm}$. These observations demonstrated that the $\mathrm{CB}$ nanoparticles are aggregated into non-spherical clusters in the polymeric matrix.

4.2 Modification of the mechanical reinforcement by incorporation of $\mathrm{CB}$

The Young modulus $Y$ is an important parameter influencing the $M$ coefficient, and was therefore determined in tensile mode for all samples with a thickness of $50 \mu \mathrm{m}$. 
In Fig.2, the red dots correspond to experimental data of the Young modulus as a function of the $\mathrm{CB}$ volume fraction. In order to compare with already existing models developed to predict the reinforcing effect of hard particles in soft matrices, the Guth equations [20] were used as a preliminary approach for sake of simplicity. In fact, these equations have been developed for materials with Poisson ratios close to 0.5 , i.e. liquids or elastomers, in which particles are randomly dispersed.

---Fig.2---

Moreover, Guth proposed to take into account the particle shape factor $\varphi$ which, as a first approximation, is the averaged ratio of the largest dimension over the smallest dimension of particles:

$$
Y=Y_{0}\left[1+0.67 \varphi f+1.62 \varphi^{2} f^{2}\right]
$$

The various dashed lines in Fig.2 correspond to different values of $\varphi$. Comparisons to experimental data indicated that the $\mathrm{CB}$ aggregates are rather elongated with $\varphi$ values between 12 and 15 . This is consistent with the "structure" of Cabot's carbon blacks as dispersed aggregates. The CB used in this study, Vulcan XC72R, is one of high structure black grades from Cabot. Consequently, the electrical conductivity of $\mathrm{CB} / \mathrm{PU}$ composites particularly shows a non-universal conducting behavior, further discussed in the next part.

\subsection{Electrical conductivity and percolation threshold}

Conductive carbons are often used to gain dielectric properties in insulating polymeric matrixes. In this work, the aim was to increase the dielectric constant and determine how it impacts the electromechanical activity of PU. Cameron et al. [21] have shown that it is possible to reach very high values very close to the percolation 
threshold where $\varepsilon^{\prime}{ }_{r}$ is expected to diverge. They have been able to fabricate actuators with a very high efficiency, demonstrating an increase in stress by a factor of 500 .

The electrical conductivity and the dielectric constant were measured using the impedance-meter. From the obtained data plotted in Fig.3(A), it is clear that the conductivity increases rapidly around $\mathrm{CB}$ contents of 1 to $2 \mathrm{v} \%$. Such a behavior is characteristic of a percolation phenomenon and it is classical to verify whether the common theory applies. Eq.(10) recalls the typical behavior of the conductivity close to the percolation threshold:

$\sigma=\sigma_{0} \cdot\left[\frac{f-f_{C}}{1-f_{C}}\right]^{t}$

where $\sigma_{0}$ is the conductivity of the conductive filler (here, $4000 \mathrm{~S} / \mathrm{m}$ for Vulcan $\mathrm{XC72R}$ ), and $t$ is the percolation exponent. For randomly dispersed particles and for perfectly conducting (i.e. uniform) particles, it has often been pointed out that a universal couple of parameters $\left[f_{c}, t\right]$ can be determined (both experimentally and by simulation), depending only on the particle shape.

---Fig.3---

From the data in Fig.3(B), an optimization of the plot of $\log \left(\sigma^{*}\right)$ versus $\log \left[\frac{f-f_{C}}{1-f_{C}}\right]$, so as to obtain a straight line, rendered it possible to determine both $f_{c}$ and $t$. Thus, $f_{c}$ was found to be $1.24 \mathrm{v} \%$ and $t$ was 2.8 . It was also seen that the composite microstructure is in reasonable agreement with the main hypothesis of the percolation theory (random dispersion of individual particles). The very low value of the percolation threshold is typical of the presence of aggregates of very small native particles, which is the case for CB. In previous works [21, 22], it was argued that the 
exponent $t$ depends on the particle shape: $t=2$ corresponds well for spherical particles, while rods lead to $t=3$.

On the other hand, another explanation was proposed by Balberg [23]. He used a simple model based on interparticle tunneling conduction and percolation network to explain the universal and non universal behaviors of the electrical conductivity of CBpolymer composites. The model clearly indicated that the universal behavior occurs in case of the high structure CB composites with a $t$ exponent close to the universal $t_{u n}=2$ and a low $f_{C}$. Contrariwise, the non universal behavior occurs in the lower structure $\mathrm{CB}$ composites which yield a larger $t$ and a higher $f_{C}$. In the case of CB primary particles individually dispersed into insulating matrix, a non universal behavior may lead to a high critical exponent $t$, i.e., $t=4$ from the Mogul-L composite [23] and even higher $t=$ 6.4 predicted by a tunneling-percolation model for system having an ideal random like Hertz distribution [24].

In the previous measurements of Balberg on Cabot black composite, a high non universal exponent $t=2.8$ was found in [23], exactly the same value of our result. It is due to the fact that the Cabot black we used is intermediate-structure compared to a normal high-structure and another no-structure CB composite.

\subsection{Dielectric properties}

Composites with $\mathrm{CB}$ fractions lower than the percolation threshold are mainly insulators and their dielectric permittivity can be measured. Fig.4 exhibits the dielectric constant versus the $\mathrm{CB}$ contents at different frequencies.

---Fig.4---

Fig.4(A) shows that, regardless of the sample, the dielectric constant increases as the frequency is lowered. Close to the percolation threshold, the composites present a 
high dielectric constant $\varepsilon^{\prime}{ }_{r} \approx 53$ at $0.1 \mathrm{~Hz}$, i.e. about 7 times higher than that for pure $\mathrm{PU}$ (for which $\varepsilon^{\prime}{ }_{r} \approx 7$ ). By means of another percolation equation, it was possible to verify that the theory applied reasonably well:

$\mathcal{E}^{\prime}=\mathcal{E}_{M}^{\prime} \cdot\left[1-\frac{f}{f_{C}}\right]^{-q}$

Here, $\varepsilon^{\prime}{ }_{M}$ is the pure polymer dielectric permittivity and $q$ is the critical exponent experimentally found near $0.8-0.9$, which is typical for most of the composites based on an elastomeric matrix and CB [25, 26].

Here again, a linear relation between $\log \left(\varepsilon_{r}^{\prime}\right)$ and $\log \left[1-\frac{f}{f_{C}}\right]$ renders it possible to verify that the obtained data are consistent with the hypothesis involved in the percolation theory. The critical exponent $q$, with a value around 0.85 , agrees well with the results from the percolation model of conductive particle-filled composites [27]. Below the percolation threshold, $\varepsilon_{r}^{\prime}$ can reach high values and the electric losses remain low. On the contrary, above the percolation threshold, both components namely $\varepsilon_{r}^{\prime}$ and $\varepsilon^{\prime \prime}{ }_{r}$ increase. The latter parameter, which is a direct probe of the electrical loss, is found to increase even more rapidly. One way to visualize this would be to plot the ratio $\varepsilon^{\prime \prime}{ }_{r} / \varepsilon_{r}^{\prime}$, also known as tan $\delta$ or loss factor, versus the $\mathrm{CB}$ contents at different frequencies, as shown in Fig 5.

--Fig.5---

For an increasing $\mathrm{CB}$ fraction in the PU, the dielectric constant first increases whereas the dielectric loss factor remains constant below the percolation threshold, $f<$ $f_{c}$. Above $f_{c}, \tan \delta$ increases, which means that the imaginary part of the dielectric 
constant increases more rapidly than the real part, $\varepsilon^{\prime}$. This can be explained by the DC conductivity allowed within the percolating CB network.

The dielectric loss factor depends on the applied field frequency. At room temperature, the two components of the dielectric properties of PU, $\varepsilon^{\prime}$ and $\varepsilon "$, consistently increase at low frequencies, where more effective polarizations can temporarily occur, e.g. orientating, interfacial, and/or ionic polarizations [28].

\subsection{Electromechanical activities}

When films are subjected to small electric field variations (triangular potential at $0.1 \mathrm{~Hz}$ ), it is possible to detect small thickness variations using an interferometer. The relative thickness deformation $S_{Z}$ was measured along the $Z$ axis, normal to the main surfaces of the sample.

---Fig.6---

Fig.6 reveals that the frequency of the time dependence of the electric fieldinduced thickness strains $S_{Z}$, of pure PU with $50 \mu \mathrm{m}$ thickness, as well as for the composite films is twice that of the applied voltage. This is clearly evidence of the electromechanical behavior of the PU films being electrostrictive in nature and exhibiting quadratic strain versus electric field, according to Eq.(5). It is worth noticing that the thickness strain is negative, which indicates a compression of the film. Thus, if intrinsic electrostriction is the predominant mechanism, as discussed later, and the

electrostrictive coefficients $Q_{33}$ and $M_{33}$ are negative, as is usually found in cases of isotropic polymeric materials $[13,29]$, the residual strain will be systematically observed, due to the strain relaxation times of the polyurethane composites film. The magnitude of the residual strain is enhanced for increasing cycle numbers.

---Fig. 7--- 
Depending on the electric field magnitude $E$, two distinct strain behaviors can be defined, regardless of whether the PU is filled or not (Fig.7): (i) a quadratic behavior in the low electric field region, where $S_{Z}$ increases linearly with $E^{2}$, according to Eq.(35), and (ii) an asymptotic behavior, where $S_{Z}$ remains constant in the high $E$ region up to electrical breakdown. Larger saturation strain is found compared to those given in the previous work by Guiffard et al [6], although these authors studied the same composite system $\mathrm{CB} / \mathrm{PU}$. The difference mainly originated from the elaboration process of the films and the strain measurement conditions. In [6], the thickness strain was measured on samples systematically glued on a rigid substrate.

In the present work, only quadratic strain variation (i) was analyzed. Fig.8 shows the dependence of $S_{Z}$ versus $E^{2}$ for varying $\mathrm{CB}$ contents at a given film thickness. The absolute value of the apparent electrostrictive coefficient $-M$ is equal to the slope of the straight lines $-S_{Z}$ versus $E^{2}$ in the low electric field regime $(E \leq 4$ $\mathrm{V} / \mu \mathrm{m})$.

---Fig.8---

As shown in Fig. 8(A), both the 1.5 and 2 v\% CB/PU composites present a linear strain variation versus $E^{2}$, although only for electric fields below $2 \mathrm{~V} / \mu \mathrm{m}$. Above this value, the electric field-induced strain became non-linear and $M$ can no longer be defined. This is due to the fact that the composites with filler contents above the percolation threshold loose their dielectric nature during compression, thus becoming progressively conductive. Furthermore, as the $\mathrm{CB}$ content above $f_{c}$ is further increased then $-M$ starts to decrease. This is consistent with the electric loss increase due to the Joule effect through the conducting CB network. 
Compared to the activity of pure PU, the composites filled with CB in amounts below the percolation threshold present increasing strain values as the $\mathrm{CB}$ fraction is raised. Thus, at $E=4 \mathrm{~V} / \mu \mathrm{m}$, the $1.25 \mathrm{v} \% \mathrm{CB} / \mathrm{PU}$ is compressed by $-12 \%$, which is almost 3 times higher than for pure PU. The absolute value of the experimentally determined apparent electrostrictive coefficient $M_{\text {exp }}$ is raised from $-3 \times 10^{-15} \mathrm{~m}^{2} / \mathrm{V}^{2}$ for pure PU to $-8 \times 10^{-15} \mathrm{~m}^{2} / \mathrm{V}^{2}$ for $1.25 \mathrm{v} \% \mathrm{CB} / \mathrm{PU}$, Fig.8(B). Based on Eq.(4), it is possible to calculate the Maxwell stress contribution to the (global) apparent electrostriction, since both the dielectric constants and the Young modulus have been determined. The obtained data are displayed in Table 1, and compared to the experimental results.

---Table 1---

It was found that $S_{\text {Max }}$ represents less than $0.5 \%$ of the total strain. Consequently, it could be concluded that the electrostriction is only intrinsic in nature: $S=S_{E}$. However, the strain increase observed after filling the matrix with $1.25 \mathrm{v} \% \mathrm{CB}$ is roughly half that of the dielectric constant. Considering Eq.(6), this observation already indicates that the electrostrictive coefficient $Q$ is not constant when CB particles are incorporated in the PU matrix.

4.6 Comparison between experimental data and theoretical estimations

As shown above, the apparent electrostrictive coefficient $M_{\text {exp }}$ could be estimated from the strain measurements. Furthermore, $M$ is also theoretically related to the dielectric constant $\varepsilon_{r}^{\prime}$ and the elastic modulus $Y$ with the following relation obtained by combining Eq.(6) and Eq.(7):

$|M| \propto \frac{\varepsilon_{0} \cdot\left(\varepsilon^{\prime}{ }_{r}-1\right)^{2}}{Y . \varepsilon_{r}^{\prime}}$ 
---Fig.9---

A linear relationship between $M_{\exp }$ and $\frac{\varepsilon_{0} \cdot\left(\mathcal{E}_{r}^{\prime}-1\right)^{2}}{Y \cdot \mathcal{E}^{\prime}{ }_{r}}$ is shown in Fig.9, thus validating the empirical relationship given in Eq.(6) and Eq.(7). The neat PU and the $\mathrm{CB} / \mathrm{PU}$ composites show high strains with $M \sim 10^{-15} \mathrm{~m}^{2} / \mathrm{V}^{2}$ under a relatively low electric field at $100 \mathrm{mHz}$.

It should be noted that electrostriction phenomena in electroactive polymers are extremely frequency-dependent [30], and a large decrease of the electrostrictive coefficient with an increasing frequency is systematically observed, mainly triggered by the same frequency response of the dielectric constant. Consequently, the obtained results should only be compared with previously published data obtained for near-low frequencies.

Park and co-workers [31] have measured negative out-of-plane strain in polyimide matrix composites in response to a low-frequency $(20 \mathrm{mHz})$-applied electric field and have found similar electrostrictive coefficients $\left(M=-3.8 \times 10^{-15} \mathrm{~m}^{2} / \mathrm{V}^{2}\right)$.

---Fig.10---

The experimental value of the intrinsic electrostrictive coefficient $Q_{\text {exp }}$ can be determined from experimentally obtained data of the apparent electrostrictive coefficient $M_{\text {exp }}$ using Eq.(6). $Q_{\exp }$ was plotted versus the CB contents (Fig.10A) and versus the proportional ratio of the elastic modulus and the dielectric permittivity (Fig.10B). In Fig. 10 (A), $Q_{\exp }$ can be seen to vary in the opposite way as to $M$, which implies that materials with a large dielectric permittivity can produce elevated strains despite their small $Q$ coefficients [32]. The decrease in $Q$ is caused by the increase in $\mathcal{E}_{r}^{\prime}$ and $Y$. Nonetheless, it is also possible that the microstructure of the PU matrix is 
modified with the incorporation of CB. This would correspond to a slight change of the crystallites' morphology and texture, which in turn might increase both the Young modulus and the dielectric constant. However, such a hypothesis has to be confirmed by further experiments such as Differential Scanning Calorimetry. As expected, the empirical linear relationship in $\operatorname{Eq}(7)$ between $Q_{\text {exp }}$ and the inverse of the product of the Young modulus and the dielectric permittivity was validated in Fig.10(B). It was thus possible to predict the $Q$ coefficient from dielectric and mechanical measurements for a series of composites.

\section{Conclusions}

Polyurethane elastomers are good candidates for the processing of electromechanical actuators for several reasons: (i) their strong polarity which facilitates the dispersion of CB through the use of a polar solvent, and (ii) their ability to develop intrinsic electrostriction, in addition to simply the Maxwell effect.

It becomes clear that adding conducting particles at fractions lower than the percolation threshold can enhance the dielectric constant of PU and consequently its electromechanical activity, even if electrostriction represented by the $Q$ coefficient is decreased. Despite this antagonistic effect, an optimal CB concentration in the vicinity of the percolation threshold $\left(f_{c}=1.25 \mathrm{v} \%\right)$ yields a remarkable threefold increase in the absolute value of the apparent electrostriction coefficient $M$ at low frequency $(0.1 \mathrm{~Hz})$. On the other hand, above the percolation threshold, as the DC conductivity starts to be responsible for energy dissipation, the electrostriction efficiency starts to decrease.

In fact, the amplitude of the nanocomposite electrostriction appears to result from the competition of 3 phenomena: (i) the stiffness of the matrix (which increases with the concentration of fillers $f$ ), (ii) the dielectric constant, which also increases with 
$f$, and (iii) the DC conductivity, which is almost negligible below the percolation threshold $f_{c}$, but increases rapidly at higher contents. Nevertheless, further studies are required to understand the electrostriction physics with the aim of optimizing the energy conversion efficiency.

A linear theory of electrostriction was developed using simplified assumptions for unstressed isotropic materials, typically appropriate for small deformations [33]. This led to a relationship between the dielectric and strain tensors, the electrostatic (Maxwell) stress tensors, describing the electric field-induced forces and the resulting deformation of a linear dielectric material. Thus, another hypothesis regarding the compressible behavior of materials known as electrostriction, which is always assumed to be negligible for the ideal dielectric elastomers [34], might have to be reconsidered and may turn into a valuable field-induced strain when the volume changes and influences their physical properties, dielectric and electromechanical activities [35].

A stressed material shall be seen as anisotropic when its volume changes and its dielectric properties must be described by the dielectric tensor and the components of the strain tensor for an initially isotropic elastic material [36]. The saturated state of high electric field-induced strain is a challenge to explain. On the other hand, the impacts of microstructure and more precisely of heterogeneities on the macroscopic behavior must be more deeply explored.

\section{Acknowledgements}

This work was financed by the MACODEV research foundation of the RhôneAlpes region. The Vulcan XC72R carbon black was generously donated by the Cabot Corporation, USA. The CLYM is acknowledged for the access of the FEI XL30 FEG ESEM microscope. 


\section{References}

[1] F. Carpi, D. DeRossi, R Kornbluh, R. Pelrine, P. Sommer-Larsen, Dielectric Elastomers as Electromechanical Transducers, Elsevier, 2008

[2] Y. Bar-Cohen, Electroactive Polymer (EAP) Actuators as Artificial Muscles Reality, Potential and Challenges, SPIE Press, Vol. PM98, 2001

[3] L. Lebrun, D. Guyomar, B. Guiffard, P.-J. Cottinet, C. Putson, The Characterisation of the harvesting capabilities of an electrostrictive polymer composite, Sensors and Actuators A: Physical, 2009, 153(2), p. 251-257

[4] W. Ma, L. E. Cross, An experimental investigation of electromechanical response in a dielectric acrylic elastomer, Applied Physics A: Materials Science \& Processing, 2004, 78(8), p. 1201-1204

[5] C. Huang, Zhang Q.M., Fully Functionalized High-Dielectric-Constant Nanophase Polymers with High Electromechanical Response, Advanced Materials, 2005, 17(9), p. 1153-1158

[6] B. Guiffard, L. Seveyrat, G. Sebald, D. Guyomar, Enhanced electric field-induced strain in non-percolative carbon nanopowder/polyurethane composites, Journal of Physics D: Applied Physics, 2006, 39, p. 3053-57

[7] B. Guiffard, D. Guyomar, L. Seveyrat, Y. Chowanek, M. Bechelany, D. Cornu, P. Miele., Enhanced electroactive properties of polyurethane films loaded with carbon-coated SiC nanowires, Journal of Physics D: Applied Physics, 2009, 42, p. 055503 (6pp)

[8] B. Fragneaud, K. Masenelli-Varlot, A. Gonzalez-Montiel, M. Terrones, J.-Y. Cavaillé, Mechanical behavior of polystyrene grafted carbon nanotubes / polystyrene nanocomposites, Comp Sc. Tech., 2008, 68, p. 3265-3271

[9] G. Diguet, E. Beaugnon, J.Y. Cavaillé, From dipolar interactions of a random distribution of ferromagnetic particles to magnetostriction, J. Magn. Mater 321, 2009, p. 396-401

[10] J. Su, J. S. Harrison, T. L. St. Clair, Y. Bar-Cohen, S. Leary, Electrostrictive graft elastomers and applications, MRS Symposium: FF: Electroactive Polymers, 1999, Boston, MS 
[11] R. Pelrine, R. Kornbluh, J. Joseph, R. Heydt, Q. Pei, S. Chiba, High-field deformation of elastomeric dielectrics for actuators, Mat. Sci. \& Eng. C 11, 2000, p. $89-100$.

[12] F. M. Guillot, E. Balizer, Electrostrictive effect in polyurethanes, J. Appl. Poly. Sci., 2003, 89(2), p. 399-404

[13] I. Diaconu, A. David, D.-O. Dorohoi, An experimental investigation of electroactive polyurethane, J. Optoelectron. Adv. Mater., vol. 7, No. 6, 2005, p. $2797-2801$

[14] R. Yimnirun, S. M.-L. Eury, V. Sundar, P. J. Moses, S.-J. Jang, R. E. Newnham, Electrostriction Measurements on Low Permittivity Dielectric Materials, J. Euro. Cera. Soci. 19, 1999, p. 1269-1273.

[15] S. Eury, R. Yimnirun, V. Sundar, P. J. Moses, S.-J. Jang, R. E. Newnham, Converse electrostriction in polymers and composites, Mat. Chem. \& Phys. 61, 1999, p. 18-23.

[16] G. Kofod, P. Sommer-Larsen, R. Kornbluh, R. Pelrine, Actuation response of polyacrylate dielectric elastomers, J. Intel. Mater. Syst. Struct., 14 (12), 2003, p. 787-793.

[17] Lubrizol Corporation, Technical Data Sheet 58888 NAT 021, 2007

[18] P. Tosco, L. Kosbach, Y. Yu, C. Orecchia, Gas diffusion electrodes containing modified carbon products, Cabot Corporation (Boston, MA, US), patent 6881511.

[19] Carbot Corporation, Bulk density and True density of Carbon black, 2009

[20] E. Guth, Theory of Filler Reinforcement, J. Appl. Phys., 1945, 16(1): p. 20-25

[21] C. G. Cameron, R. S. Underhill, M. Rawji, J. P. Szabo, Conductive filler elastomer composites for Maxwell stress actuator applications, Proceeding of SPIE, 2004, vol. 5385, p. 51-59.

[21] Z.-M. Dang, L.-Z. Fan, Y. Shen, C.-W. Nan, Dielectric behavior of novel threephase MWNTs/BaTiO3/PVDF composites, Mater. Sci. \& Eng. B, 2003, 103(2): p. $140-144$.

[22] L. Flandin, G. Bidan, Y. Brechet, J.-Y. Cavaillé, New nanocomposite materials made of an insulating matrix and conducting fillers: Processing and properties, Polymer Composites, 2000, 21(2): p. 165-174. 
[23] I. Balberg, Tunneling and nonuniversal conductivity in composite materials, Phys. Rev. Lett. 59, No. 12, 1987, p. 1305-1308.

[24] Z. Rubin, S. A. Sunshine, M. B. Heaney, I. Bloom, I. Balberg, Critical behavior of the electrical transport properties in a tunneling-percolation system, Phys. Rev. B. 59, No. 19, 1999, p. 12196-12199.

[25] H. Zoism, L. Apekis, M. Omastova, Electrical Properties of Carbon Black-filled Polymer Composites, Macromol. Symp. 170, 2001, p. 249-256

[26] J. Macutkevic, D. Seliuta, G. Valusis, J. Banys, V. Kuznetsov, S. Moseenkov, O. Shenderova, High dielectric permittivity of percolative composites based on onion-like carbon, Applied Physics Letters 95, 2009, 112901, p. 1-3.

[27] W.-Z. Cai, S.-T. Tu, J.-M. Gong, A Physically Based Percolation Model of the Effective Electrical Conductivity of Particle Filled Composites, Journal of Composite Materials, vol. 40, No. 23/2006, 2005, p. 2131-2142.

[28] J.-C. Dubois, Dielectric properties of polymers, Technique of Engineering.

[29] Z. Li, Z. Cheng, Piezoelectric and Electrostrictive Polymer Actuators: Fundamentals, Biomedical Applications of Electroactive Polymer Actuators, 2009, p. 319-334.

[30] Q. M. Zhang, J. Su, C. H. Kim, An experimental investigation of electromechanical responses in a polyurethane elastomer, J. Appl. Phys. 81(6), 1997, p. $2770-2776$.

[31] C. Park, J. H. Kang, J. S. Harrison, R. C. Costen, S. E. Lowther, Actuating Single Wall Carbon Nanotube-Polymer Composites: Intrinsic Unimorphs, Adv. Mater. 20, 2008, p. 2074-2079.

[32] V. Sundar, R. E. Newnham, Electrostriction, CRC Press LLC., 2000.

[33] Y. M. Shkel, D. J. Klingenberg, Material parameters for electrostriction, J. Appl. Phys. 80 (8), 1996, p. 4566 - 4572.

[34] M. Wissler, E. Mazza, Electromechanical coupling in dielectric elastomer actuators, Sensors and Actuators A 138, 2007, p. 384-393.

[35] R. A. Anderson, Mechanical stress in a dielectric solid from a uniform electric field, Physical Review B, vol. 33, No. 2, 1986, p. 1302-1307.

[36] L. D. Landau, E. M. Lifshitz, Theory of Elasticity, 3rd edition, Course of Theoretical Physics, Vol. 7, Pergamon, New York, 1970. 


\section{Figures and tables}

Fig.1: SEM observations of cryo-fractured cross-sections of a PU film containing 0.65 v\% CB at two magnifications: (A) scale bar of $2 \mu \mathrm{m}$ and (B) scale bar of $500 \mathrm{~nm}$.

Fig.2: The Young modulus as a function of the $\mathrm{CB}$ volume fraction $f$ and shape factor $\varphi$.

Fig.3: The electrical conductivity $\sigma$ of films with varying $\mathrm{CB}$ content $f$; (A) versus the frequency in $\log -\log$ scale; (B) at $0.1 \mathrm{~Hz}$ as a function of $\log \left[\frac{f-f_{C}}{1-f_{C}}\right]$.

Fig.4: Dielectric constant of the composites:

(A), versus the $\mathrm{CB}$ content in $\mathrm{v} \%$ and for different frequencies; (B), versus $\left[1-\frac{f}{f_{C}}\right]$ in a log-log plot.

Fig.5: The dielectric loss factor, tan $\delta$, versus the CB content at different frequencies.

Fig.6: (Right): A schematic drawing of the strain measurement set-up using the laser interferometer. (Left): The typical time dependence of a triangular applied voltage and the quadratic induced thickness strain. The dotted line shows the residual strain increase, cycle after cycle.

Fig.7: The typical variation of $S_{Z}$ as a function of $E^{2}$ for pure PU and the composite films.

Fig.8: Electromechanical activities under low electric fields; (A): $S_{Z}$ versus $E^{2}$, for $E \leq 4 \mathrm{~V} / \mu \mathrm{m}$; (B): the experimental apparent electrostrictive coefficient $M$ versus the CB content. For 1.5 and $2 \mathrm{v} \% \mathrm{CB}, M$ was determined at $E \leq 2 \mathrm{~V} / \mu \mathrm{m}$.

Fig.9: The experimentally obtained $M_{\exp }$ as a function of $\frac{\mathcal{E}_{0} \cdot\left(\mathcal{E}_{r}^{\prime}-1\right)^{2}}{Y \cdot \mathcal{E}_{r}^{\prime}}$. 
Fig.10: The intrinsic electrostrictive coefficient $Q$ from experimental data of the apparent electrostrictive coefficient $M$ and the dielectric constant $\varepsilon_{r}{ }_{r}$,

(A): $Q$ versus the CB content, and (B): $Q$ versus $\frac{1}{\varepsilon_{0} \cdot \varepsilon_{r}^{\prime} \cdot Y}$.

Table 1: Strain estimation from the Maxwell stress compared to the total strain of the experimental data.

\begin{tabular}{|c|c|c|c|c|c|}
\hline Composites & Experimental data & & & & Estimation \\
\hline CB contents & $\begin{array}{l}\text { Total strain } \\
E=4 \mathrm{~V} / \mu \mathrm{m}, 0.1 \mathrm{~Hz}\end{array}$ & $\begin{array}{l}\text { Apparent coefficient } \\
E \leq 4 \mathrm{~V} / \mu \mathrm{m}, 0.1 \mathrm{~Hz}\end{array}$ & $\begin{array}{l}\text { Young } \\
\text { modulus }\end{array}$ & $\begin{array}{l}\text { Dielectric constant } \\
V=1 \mathrm{~V}_{\mathrm{rms}}, 0.1 \mathrm{~Hz}\end{array}$ & $\begin{array}{l}\text { Strain from } \\
\text { Maxwell stress, Eq. } 4 \\
\text { at } E=4 \mathrm{~V} / \mu \mathrm{m}\end{array}$ \\
\hline$(\mathrm{v} \%)$ & $-S_{Z}(\%)$ & $-M \times 10^{-15}\left(\mathrm{~m}^{2} / \mathrm{V}^{2}\right)$ & $Y(\mathbf{M P a})$ & $\varepsilon_{r}^{\prime}$ & $-S_{M a x}(\%)$ \\
\hline 0 & 5.0 & 3.2 & 37 & 6.5 & 0.0025 \\
\hline 0.025 & 5.8 & 3.8 & 37 & 7.6 & 0.0029 \\
\hline 0.05 & 6.6 & 4.2 & 39 & 8.4 & 0.0031 \\
\hline 0.1 & 7.5 & 4.7 & 41 & 8.5 & 0.0029 \\
\hline 0.5 & 8.2 & 5.2 & 42 & 12.6 & 0.0043 \\
\hline 1 & 9.2 & & 43 & 29.9 & 0.0098 \\
\hline 1.25 & 12.4 & & 44 & 53.4 & 0.0171 \\
\hline 1.5 & 6.3 & $7 *$ & 46 & N/A & - \\
\hline 2 & 2.8 & $2.3^{*}$ & 49 & N/A & - \\
\hline 5 & $\sim 0$ & $\sim 0$ & 75 & N/A & - \\
\hline
\end{tabular}

* Valued at $E \leq 2 \mathrm{~V} / \mu \mathrm{m}$ 


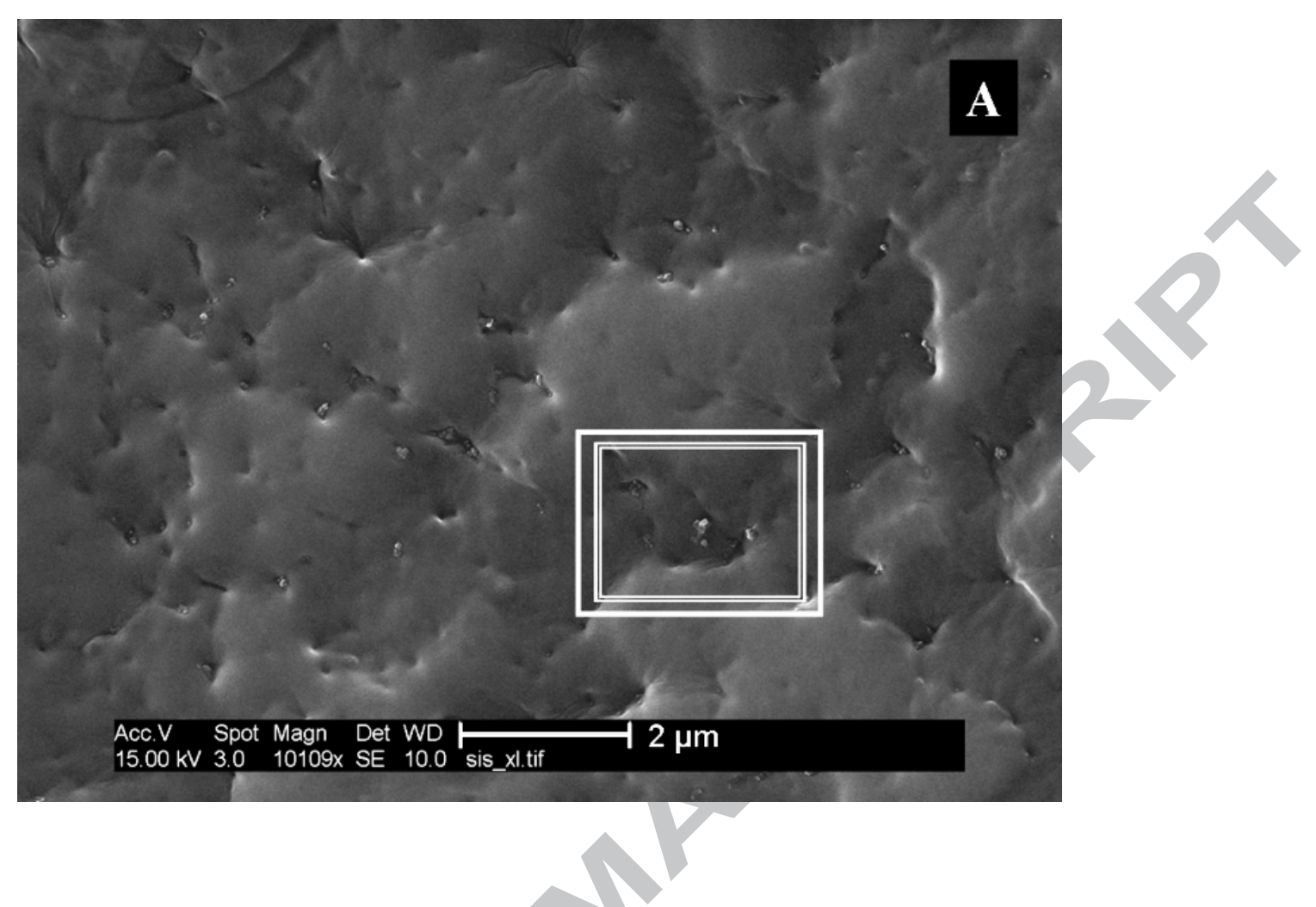

Fig 1a 


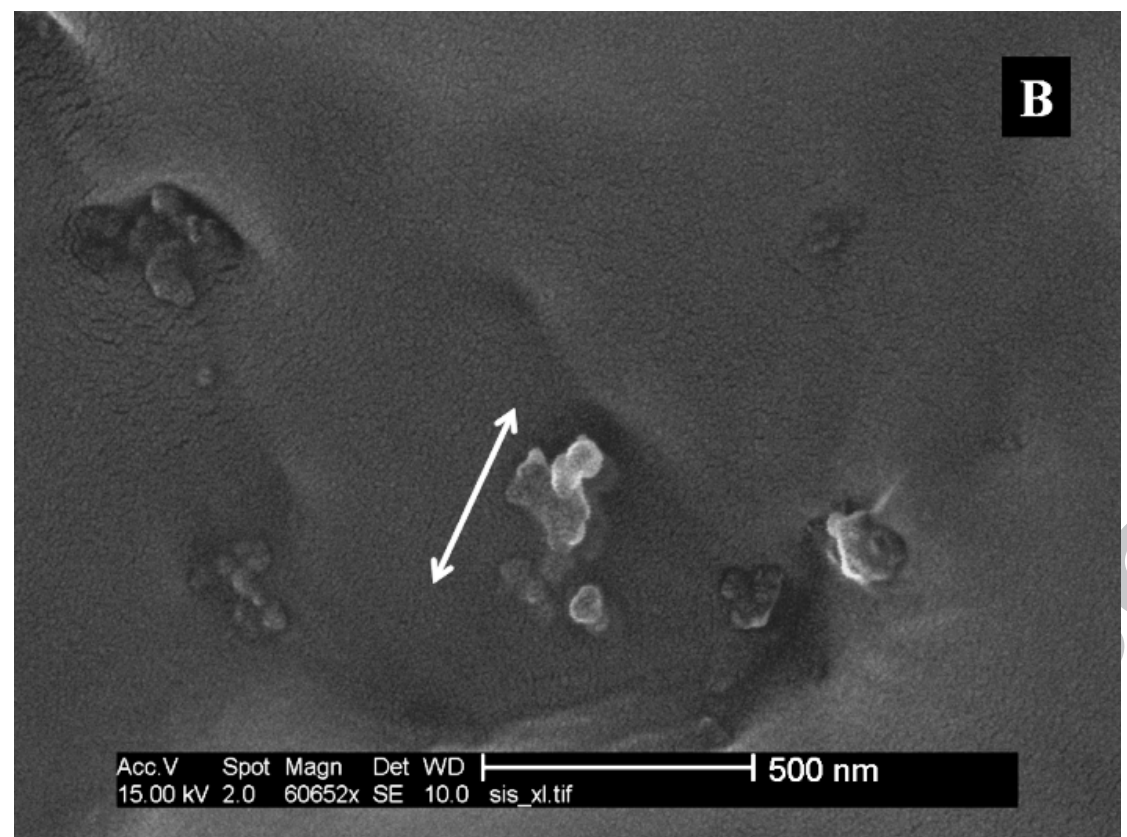

Fig $1 b$ 


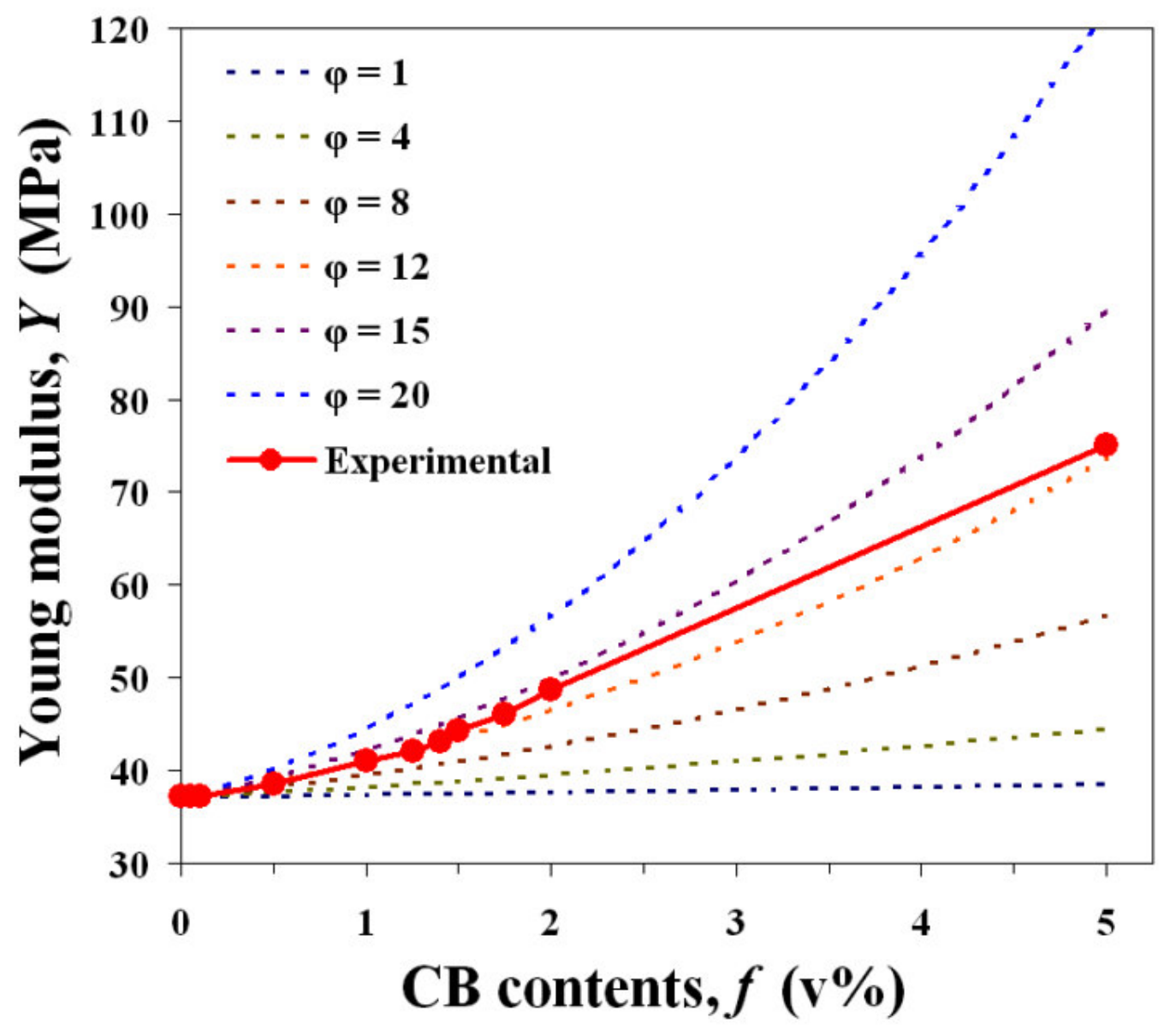

Fig 2 


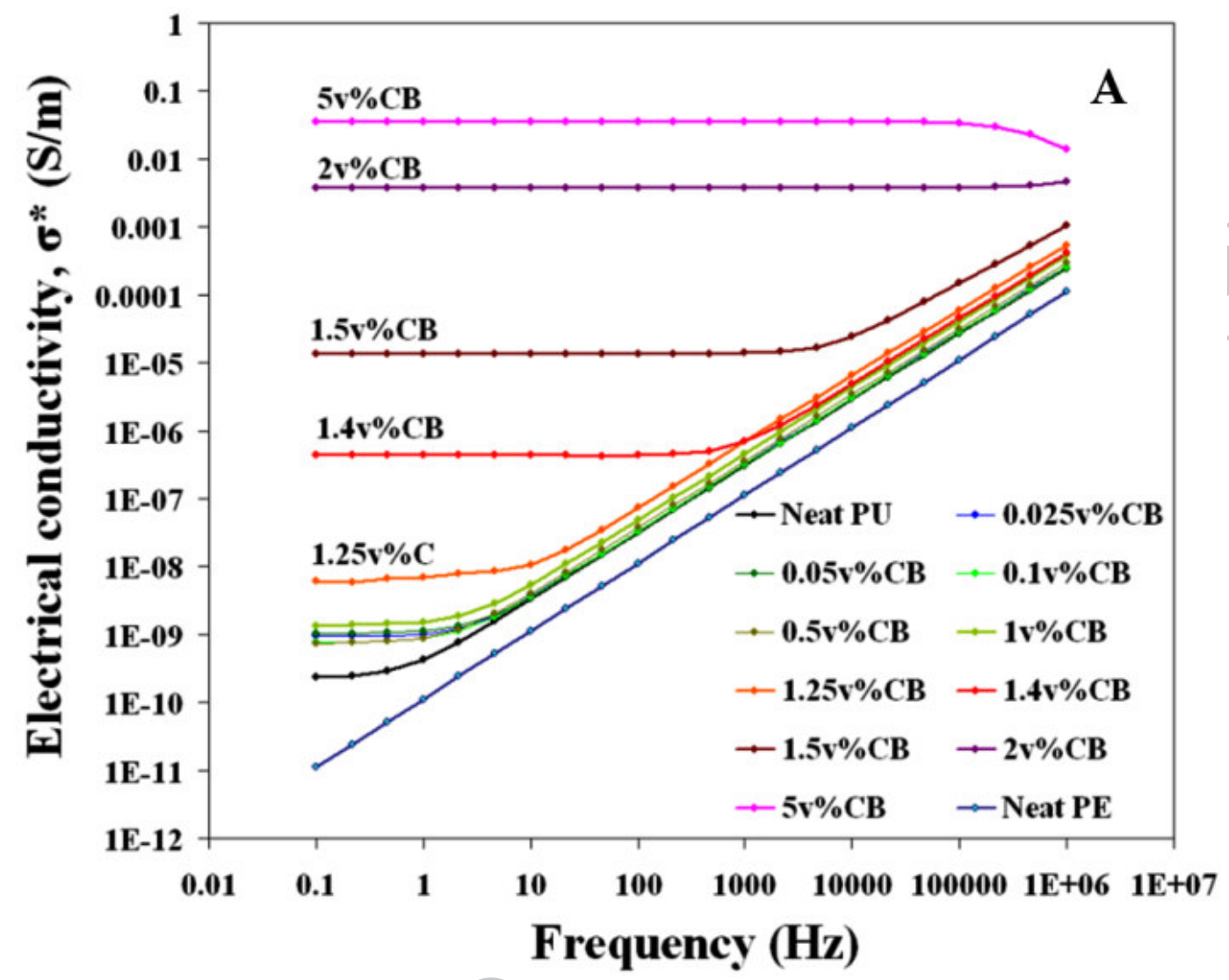

Fig 3a 


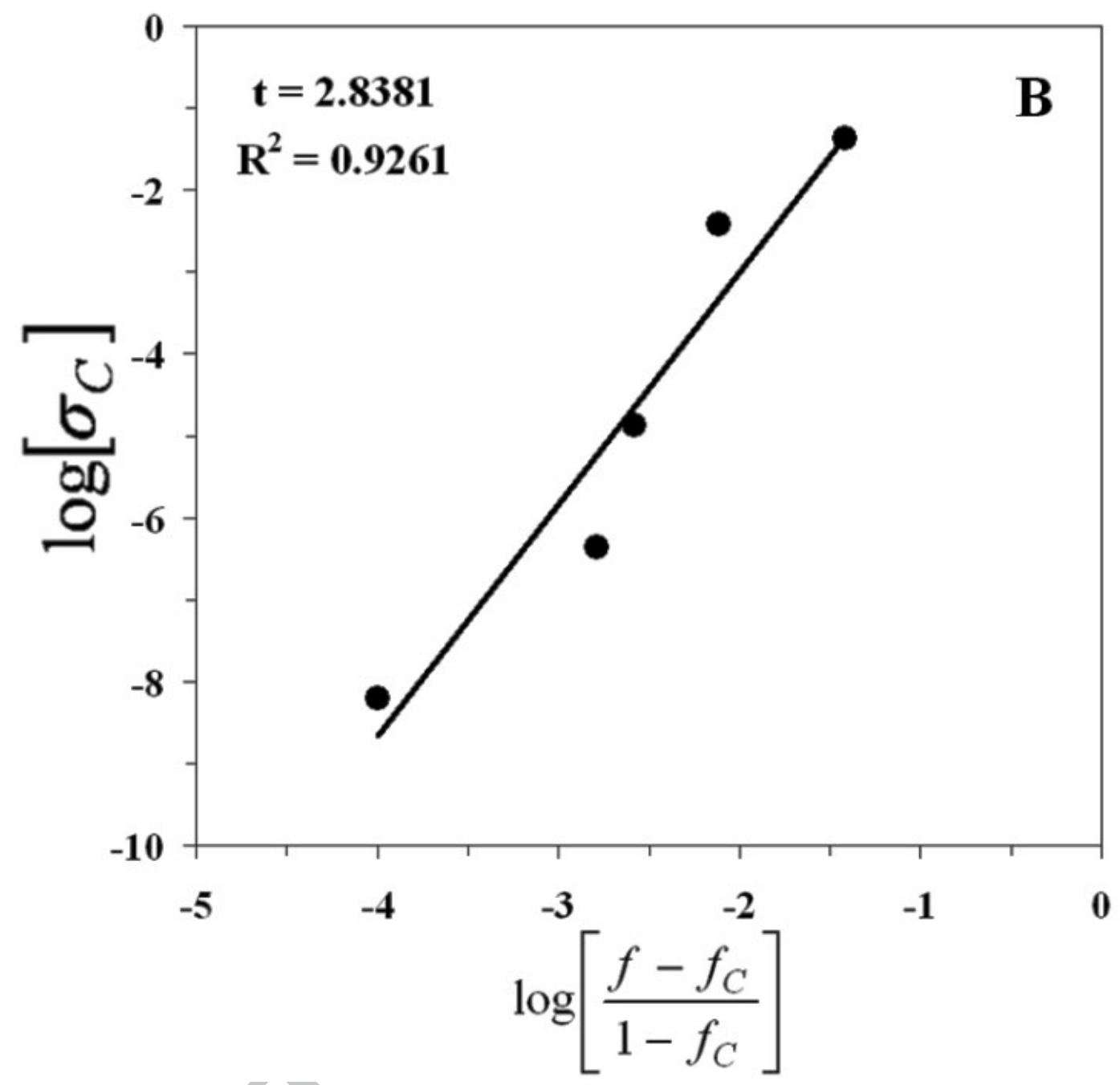

Fig 3b 


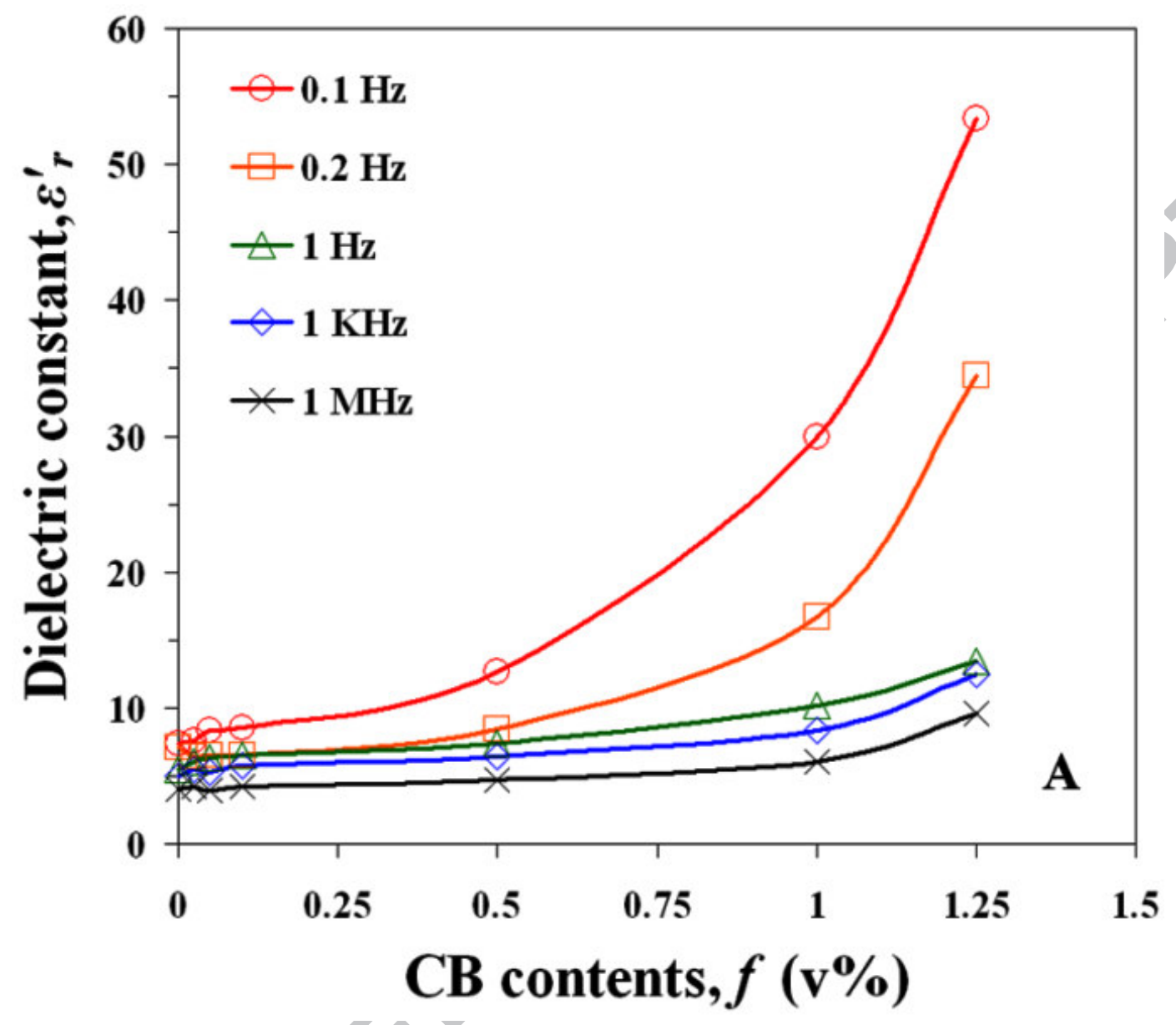

Fig 4a 


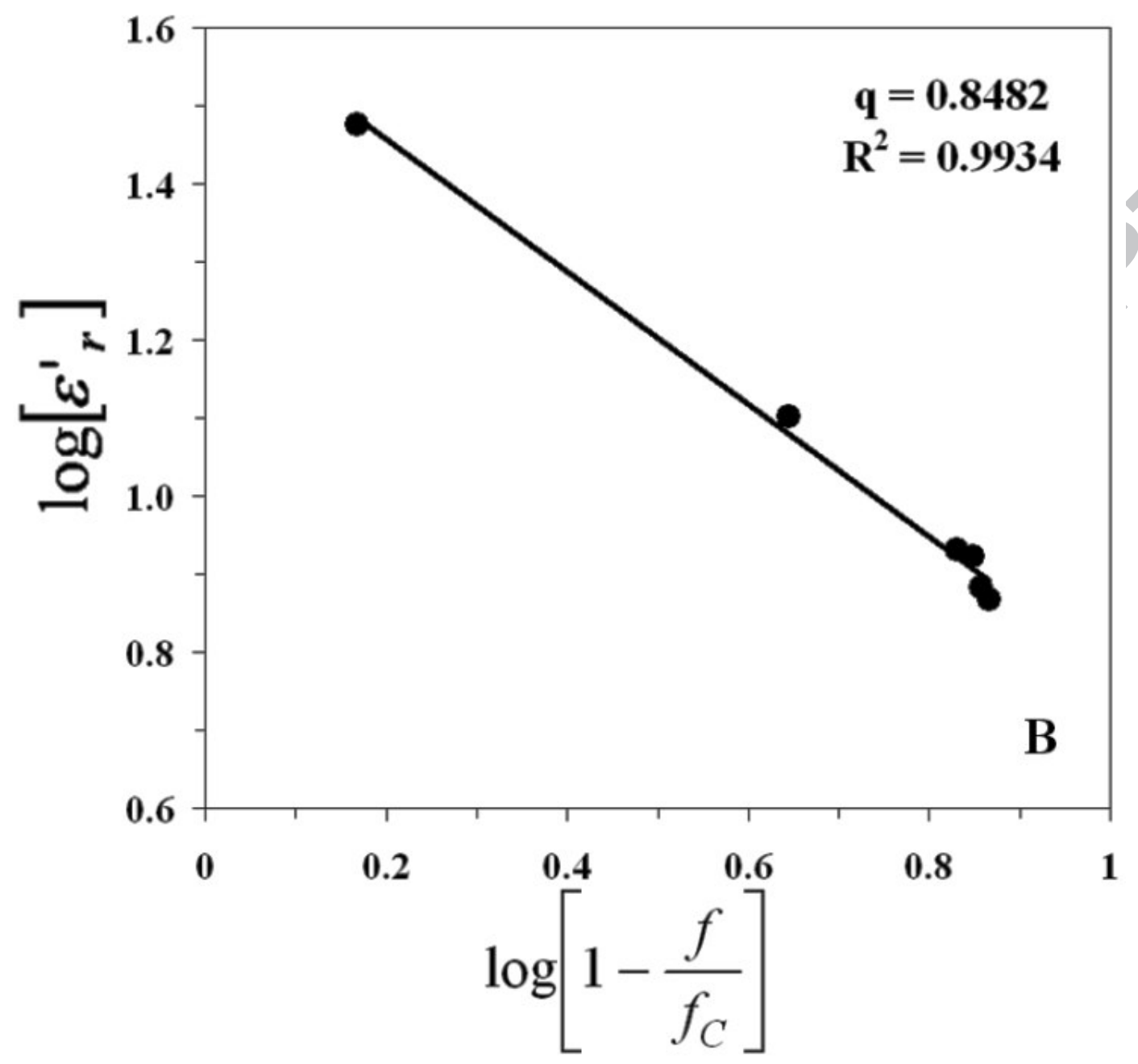

Fig $4 b$ 


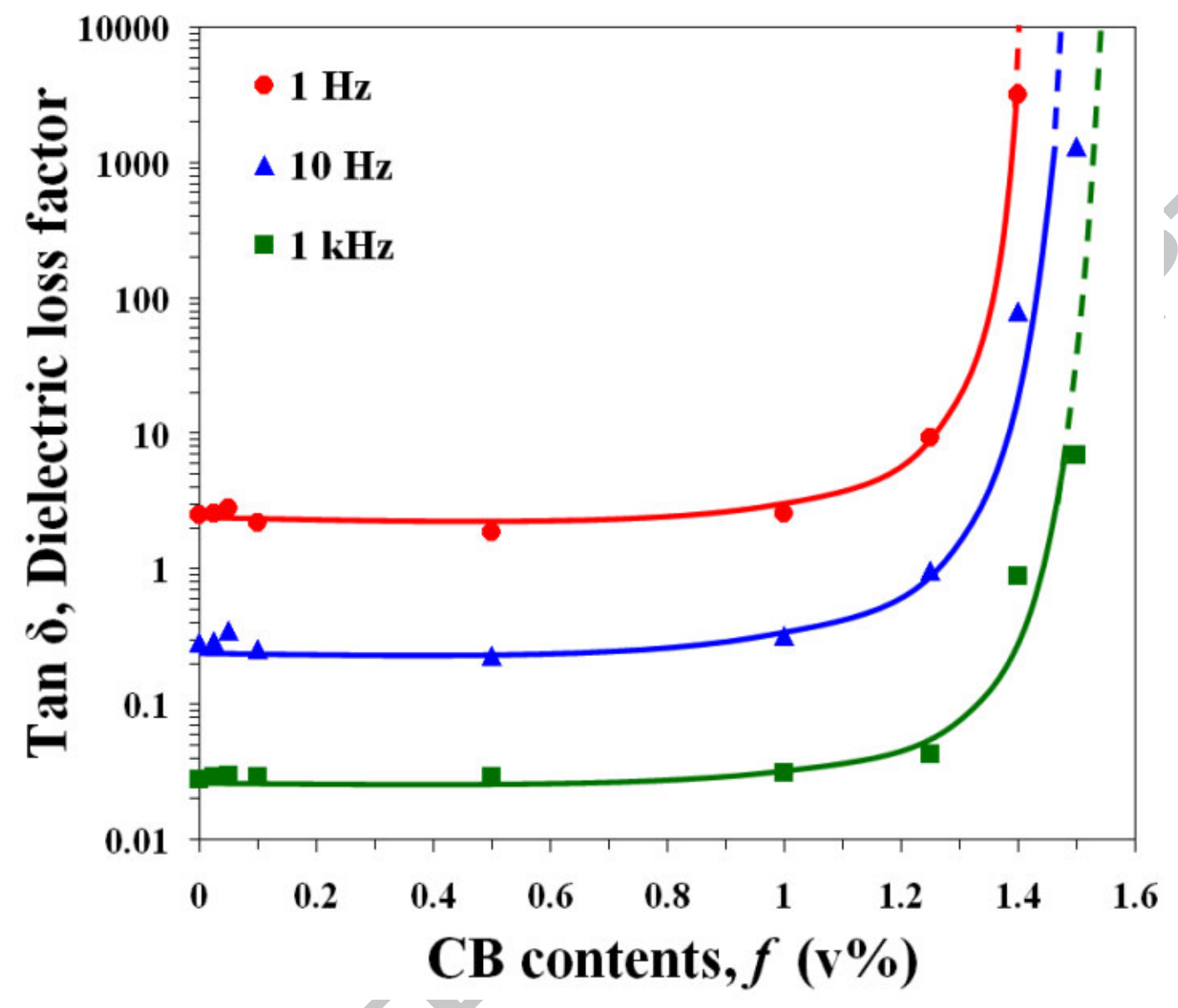

Fig 5 


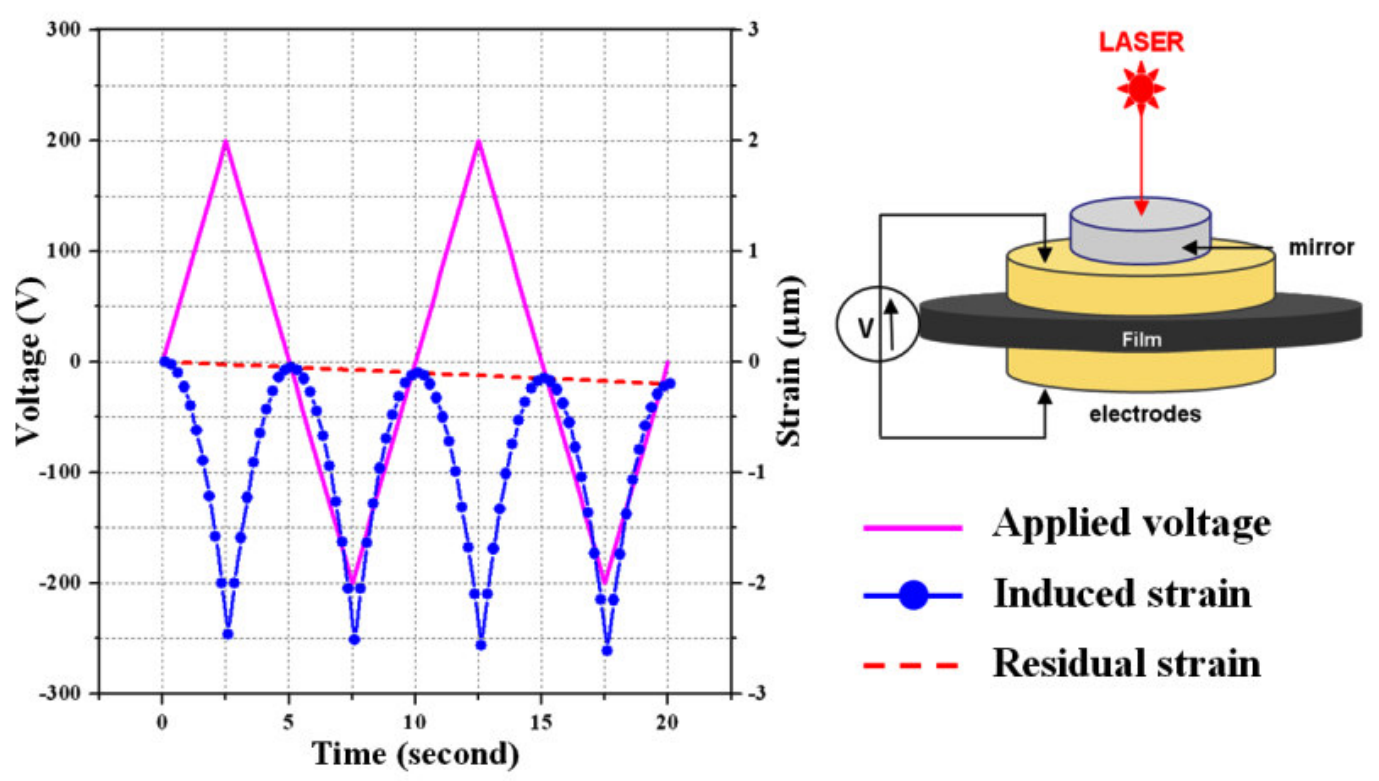

Fig 6 
ACCEPTED MANUSCRIPT

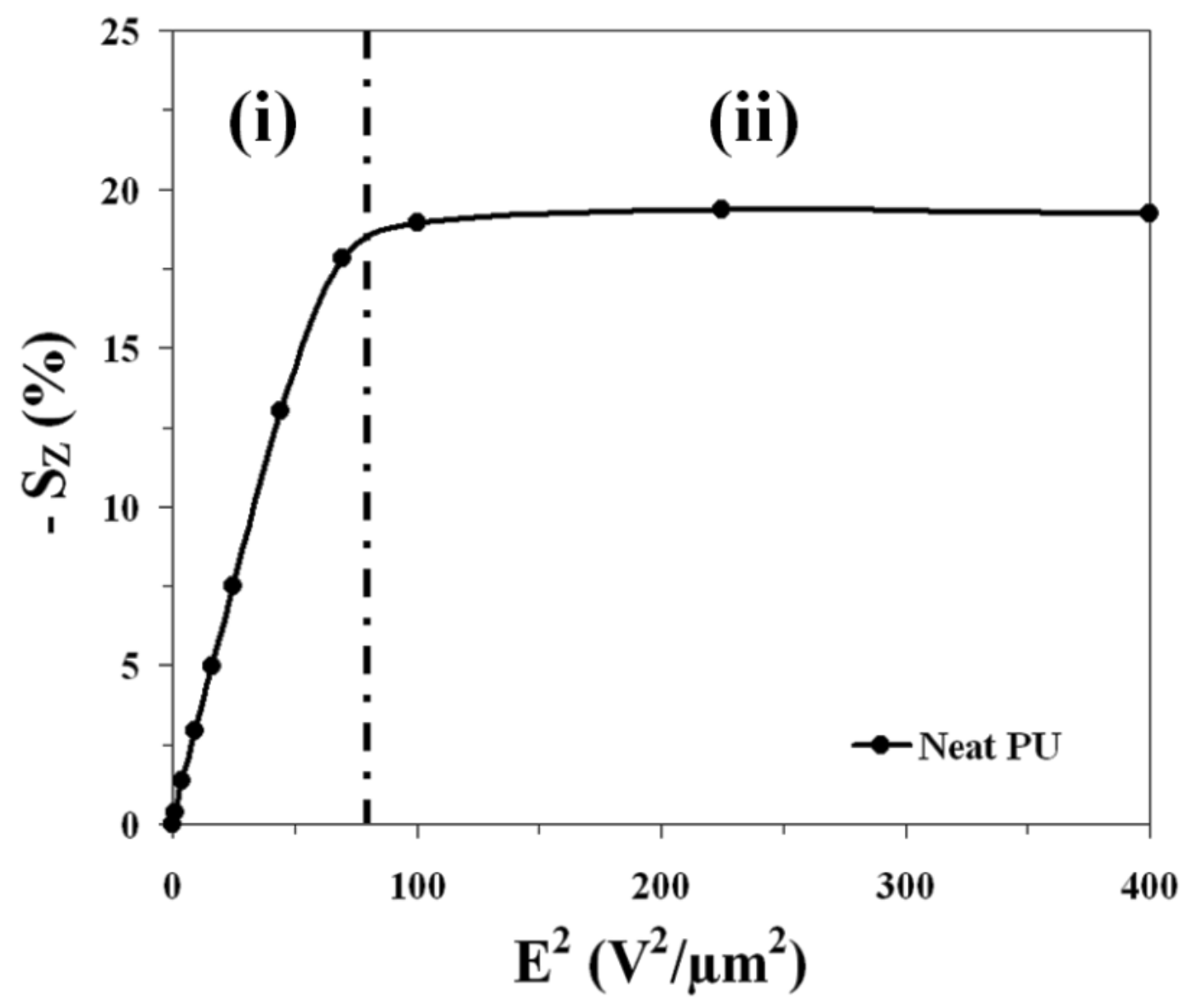

Fig 7 


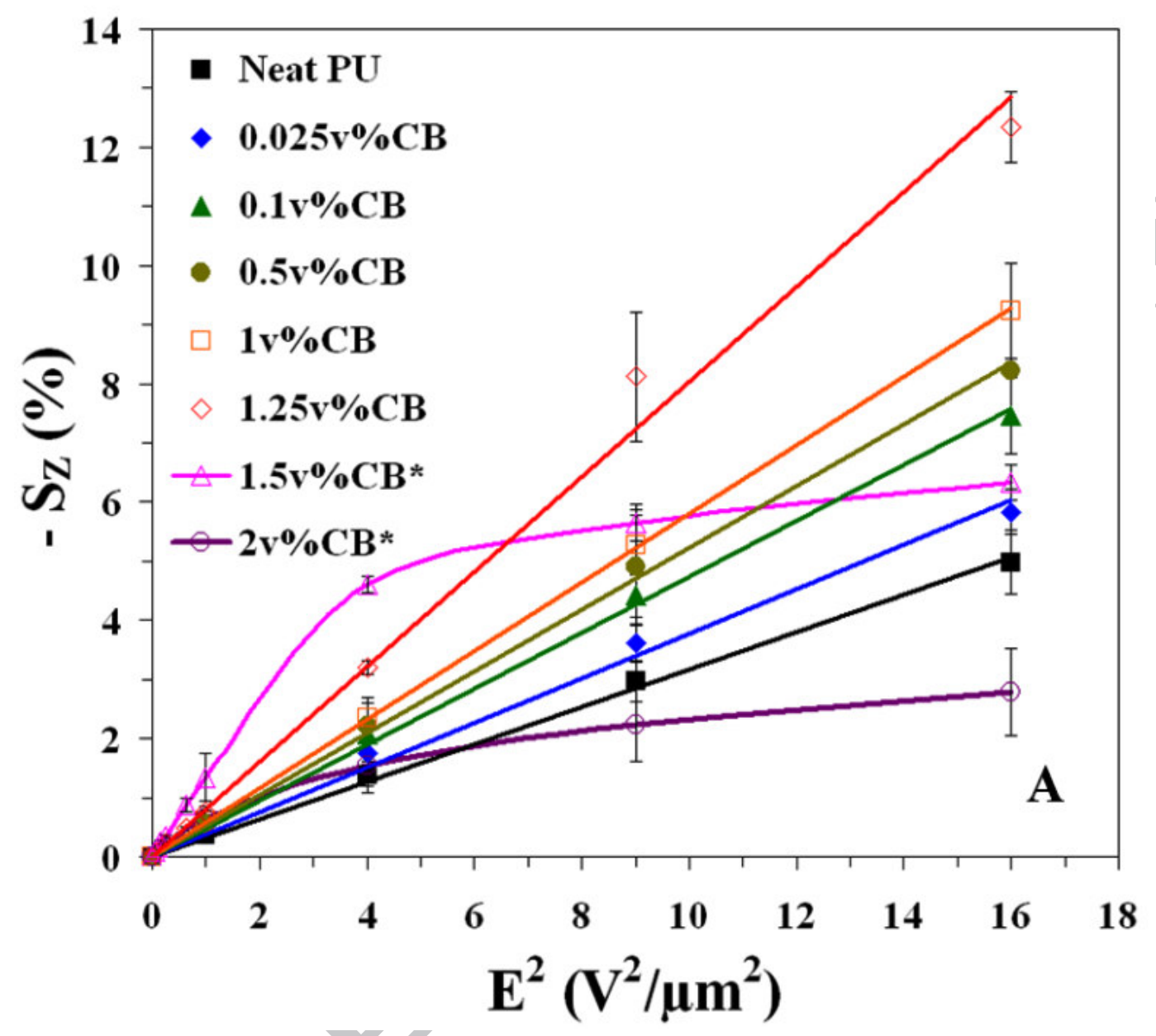

Fig 8a 


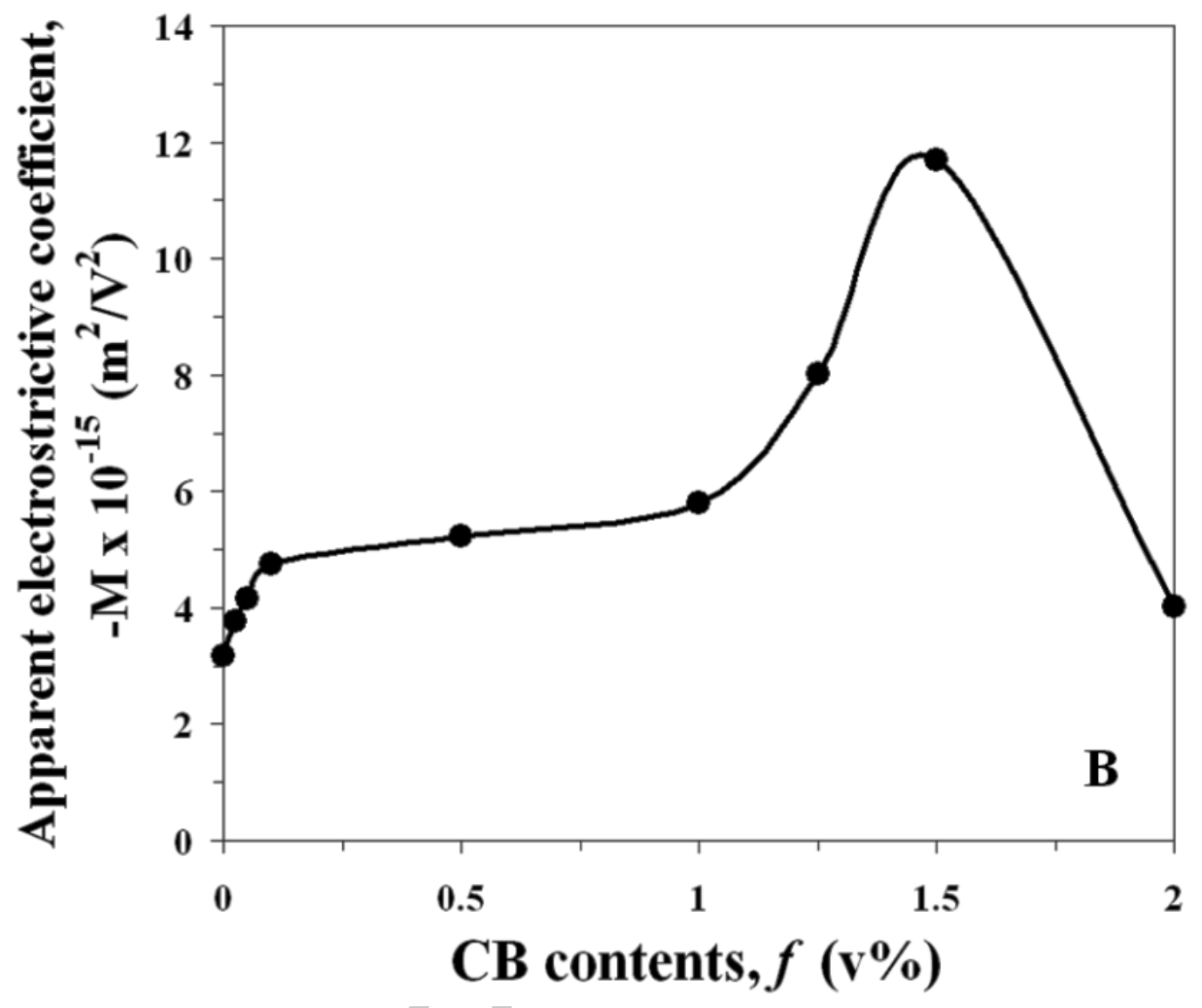

Fig $8 b$ 


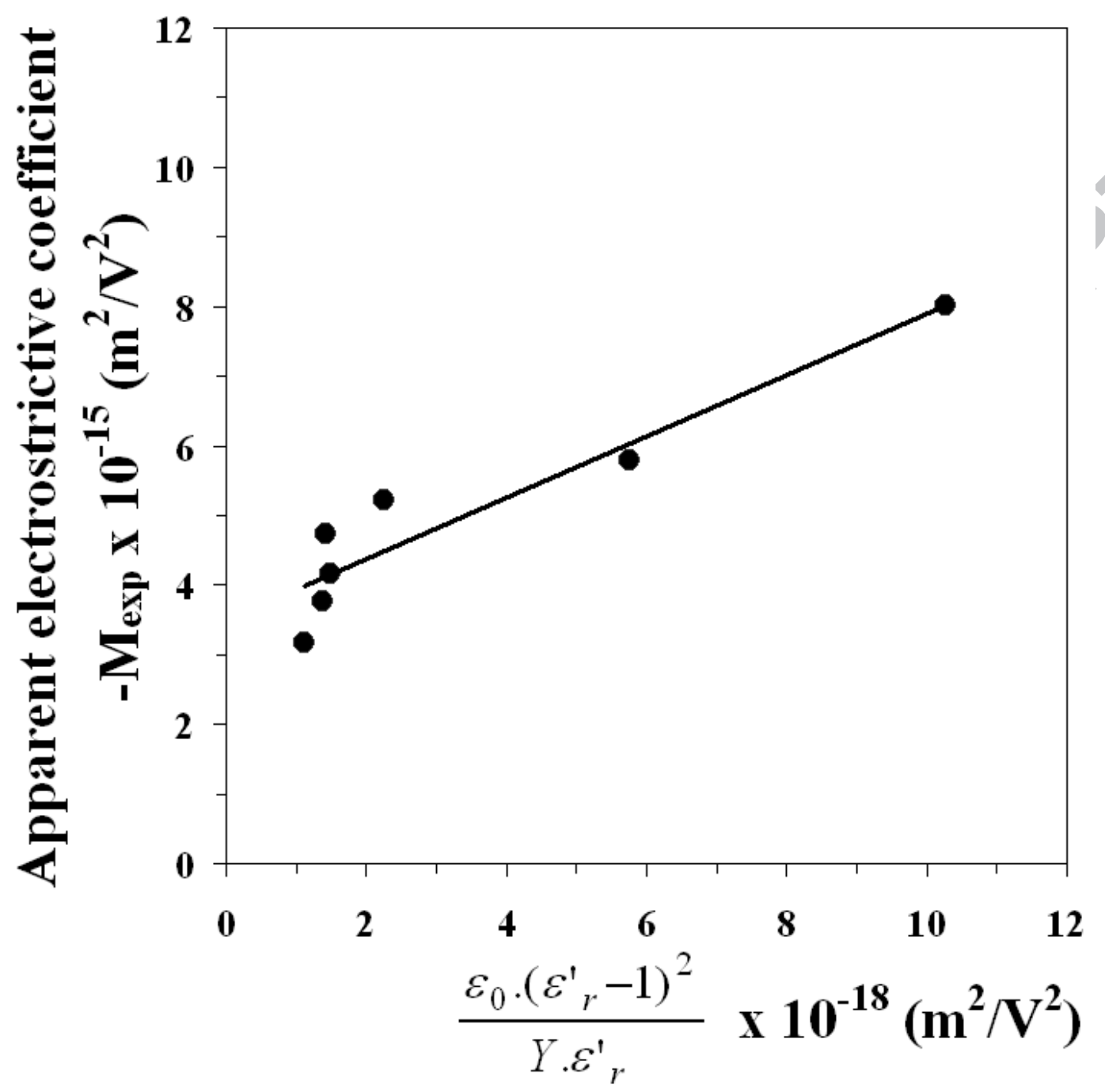

Fig 9 


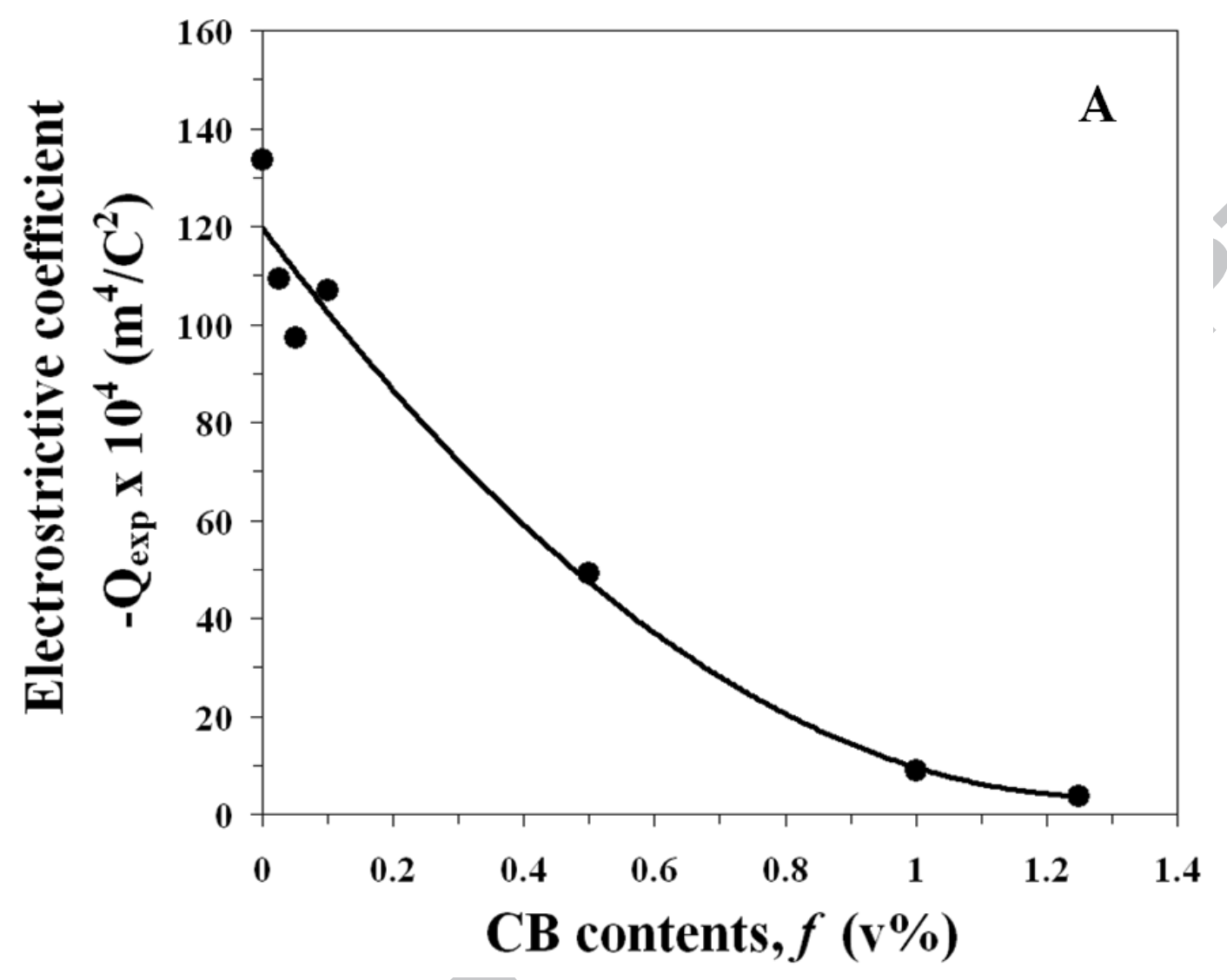

Fig 10a 


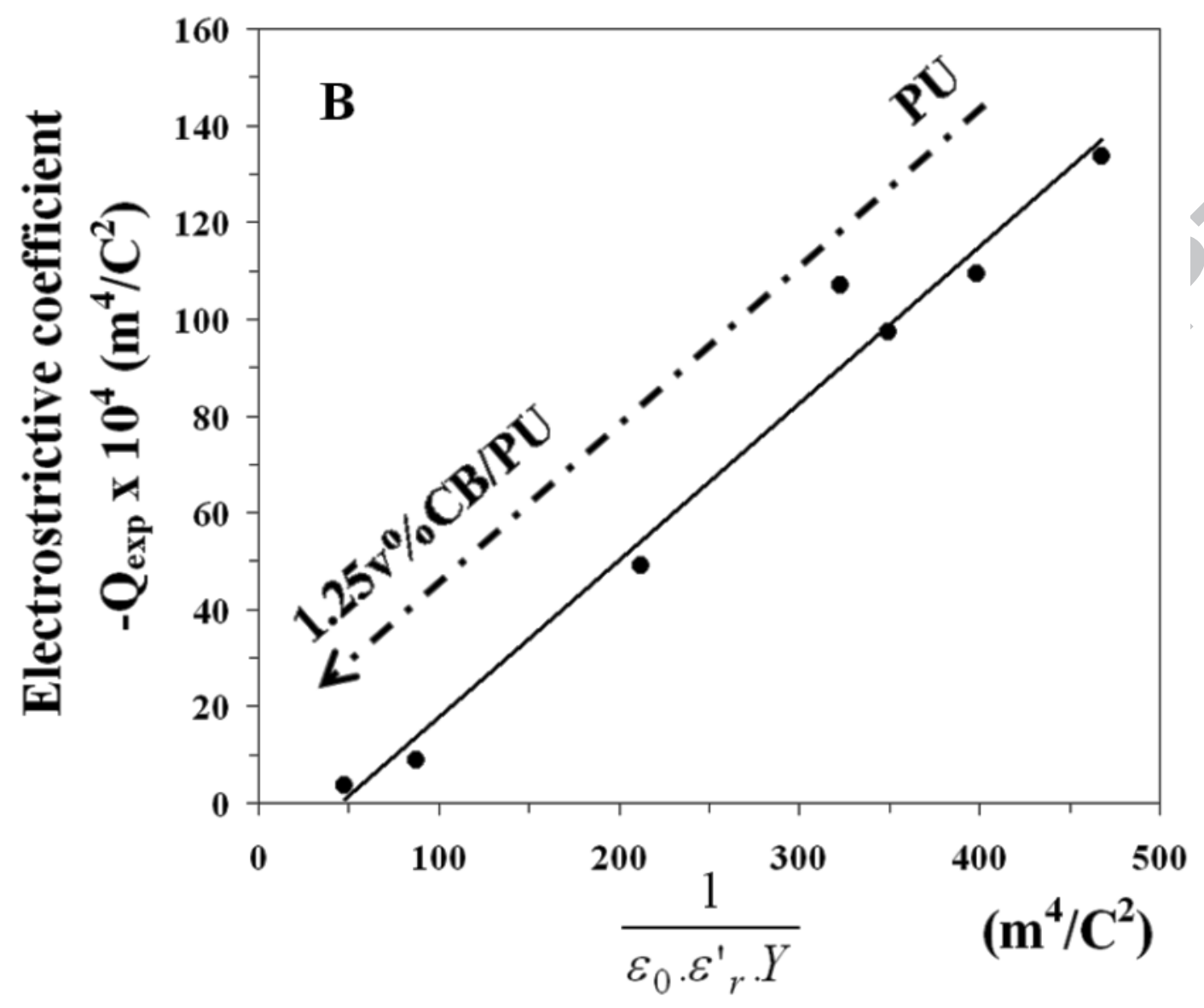

Fig 10b 